\title{
THE OUTLOOK OF SUPPLY CHAIN MANAGEMENT AMID COVID 19 PANDEMIC : AN EXPLORATIVE ANALYSIS OF RECENT RESEARCH
}

\author{
Shakila Yasmin*
}

\begin{abstract}
The outbreak of Corona virus pandemic started in China near the end of 2019. Since then, the virus has spread over all corners of the world and has been taking huge toll of people's life. The nature of contamination and spread of the virus has disrupted all sorts of business and social activities let alone the supply chains. Supply chain professionals and their stakeholders are working hand in hand to tackle the challenges and exploring ways to covert the challenges into opportunities to tap on. Scholars with interest in supply chain management are not only scrutinizing the situation but also taking up research to analyse the situation and provide data driven, knowledge-based recommendations. This research takes an explorative approach to identify the major themes, approaches, findings, recommendations generated by the body of literature focusing on supply chain management issues during and after the COVID 19 pandemic. Recent research articles on the topic are identified and downloaded using key word search from Google Scholar, Taylor \& Francis, Harvard Business Publishing, Elsevier, Wiley, Emerald and Springer sites. 20 articles were selected for in-depth analysis based on the following criteria-written in English, relevance to the topic, publication in peer reviewed journals listed in Scopus data base, and accessibility of full paper. The systematic analysis of literature done in this study helps in identification and categorization of the key research in the field in terms of their context, focus, current and potential impacts, prescribed responses, and future outlooks. The study also detects the research gaps and offers direction to advance future research on the topic. Practitioners can use the findings of the study as a reference to devise their supply chain strategies and plan of actions amid COVID 19.
\end{abstract}

Keywords: pandemic, COVID 19, supply chain management, risk, disruption

\footnotetext{
* Shakila Yasmin, $\mathrm{PhD}$ is Associate Professor, Institute of Business Administration, University of Dhaka, Bangladesh. E-mail: shakila@iba-du.edu

Social Science Review [The Dhaka University Studies, Part-D], Vol. 37, No. 2, December 2020
} 


\section{Introduction}

In late 2019, a flu-like disease triggered by Corona Virus was first spread in Wuhan city of China. Since then, the virus kept propagating across regions, took heavy toll on human lives and impacted almost every economy and geographical territory of the world. By mid-March 2020, the virus took 6,500 lives, about 300 thousand people got affected in more than 114 countries across the world (WHO, 2020). World Health Organization (WHO) declared the outbreak of this new virus as COVID 19 pandemic. To slow down the rapid contamination of the virus countries took measures like, self-quarantine, border closure, regional lock down etc. Due to these measures regular business activities got hampered in the form of reduced business hour, slashed demand, disrupted flow of material and labour supply and others. Both local and global supply chains faced tremendous challenges to cope with the situation. Some businesses (for example, hospitality sector) are struggling to survive and/or closed operations temporarily due to slow down of trade. On the other hand, many businesses are struggling hard to meet essential demand of customers due to disruptions in product, services and labour supply networks. Given the situation, professionals and academics delved into research to evaluate and project the impact of the pandemic on supply chains and to figure out ways to tackle the crisis. However, due to the recency of the crisis, the literature focusing on it still prevails in a scattered state and is not yet organized in any comprehensive repository. While doing literature review for this study only one publication has been found that has done a systematic review of literature on the impact of COVID 19 on business and management (Verma \& Gustafsson, 2020). However, this paper, just mentions supply chain management as one of the key areas being impacted by the pandemic. In this context, an overarching comprehension of the literature to date, focusing on supply chain management during COVID 19 pandemic and way forward is necessary to devise practicable strategies and operational plans for managing supply chains as such to tackle the challenges posed by the pandemic. This kind of analysis is also required to identify the gaps in existing literature and to determine new research agenda. Therefore, the author of this study likes to find out, what are the key issues and contexts covered in literature focusing on supply chain management in the context of the recent ongoing pandemic? what research methodologies have been employed by the researchers? How have the local and global supply chains affected by COVID 19 pandemic? what are the long-term impacts of COVID 19 on supply chains and their management? what can be /should be done to tackle 
the crisis and enhance resilience against such disruptions? whether there are any untapped research questions in this relation? and what further research prospects are available? This paper thereby aims for conducting an in-depth review literature focusing on supply chain management amid COVID 19 pandemic. The major objectives are to identify the supply chain issue amid COVID 19 as covered in literature; pinpoint the methodologies adopted in existing research works; comprehend the recommendations provided in literature to combat the crisis and any follow ups for the new normal operation; and determine open questions and future research opportunities in this regard.

\section{Methods}

An exploratory approach is adopted in this research. Exploratory studies heavily rely on qualitative data analysis in order to examine certain topic/ subject matter to gather a comprehensive insight about the topic and to identify certain unresolved issues or questions for further investigation (Cooper and Schindler, 2008 and Stebbins, 2001). A systematic literature review (SLR) was done to collect information and evidence for analysis. Although SLR is traditionally used in medical sciences, it is an efficient technique for summarizing results of existing literature and assessing consistency among the available studies (Petticrew, 2001). SLRs are deemed valuable particularly in situations where there is conflicting evidence in relation to the best way of doing things which is quite common in management and business. By using SLR, evidencebased recommendations can be devised for practitioners (Bell, Bryman, \& Harley, 2018).

Table 1 presents the framework for SLR. To ensure authenticity and genuineness of the research works to be reviewed for this study articles published only in peer reviewed academic journals indexed in Scopus were considered. Research papers were searched from Google Scholar, Taylor \& Francis, Harvard Business Publishing, Elsevier, Wiley, Emerald and Springer data based. Title, abstract and key words field in the data bases were searched using the following criteria'COVID 19' OR 'Corona Virus' AND 'pandemic' OR 'epidemic' OR 'outbreak' AND 'supply chain' OR 'logistic' OR 'SCM' OR 'OSCM'*. January 2020 to July 2020-ime frame was used to identify the relevant research articles. This way, 37 articles were identified. From these 37 titles, 17 were excluded due either for not being related to supply chain or logistics management and the COVID 19 
pandemic or for inaccessibility of the full paper. The author thus ended up with 20 articles for in-depth review. No bibliometric or content analysis software was used for reviewing the articles. The researcher rather read and analysed the shortlisted articles thoroughly and organized the findings through manual note keeping in excel.

Table 1: SLR framework

\begin{tabular}{l|l}
\hline Research data bases & $\begin{array}{l}\text { Google Scholar, Taylor \& Francis, Harvard Business } \\
\text { Publishing, Elsevier, Wiley, Emerald and Springer }\end{array}$ \\
\hline Type of publication & Peer reviewed journals indexed in Scopus \\
\hline Time frame & January 2020-July 2020 \\
\hline Key words & $\begin{array}{l}\text { 'COVID 19' or 'Corona Virus' and 'pandemic' or } \\
\text { 'epidemic' or 'outbreak' and 'supply chain' or 'logistic' } \\
\text { or 'SCM'* or 'OSCM'*. }\end{array}$ \\
\hline Key word search field & Titles, abstracts, and keywords \\
\hline Criteria for exclusion & $\begin{array}{l}\text { Not related to supply chain or logistics management } \\
\text { and the COVID 19 pandemic. } \\
\text { Inaccessibility of full paper. }\end{array}$ \\
\hline Data extraction and analysis & Manual reading and evaluation of the full paper \\
\hline
\end{tabular}

*SCM- Supply chain management; OSCM- Operations and supply chain management

\section{Findings}

First the uniqueness of the current pandemic situation is explained with reference to literature. Then other aspects of literature such as key issues covered, contexts, theoretical underpinning, methodologies employed, short- and long-term impacts of COVID 19, recommendations and others are presented in separate subsections. Finally, untapped research questions in relation to COVID 19 and SCM are presented.

\section{Uniqueness of the Impacts of the Pandemic}

All the research papers reviewed for this research depicted the COVID 19 situation as a unique kind of supply chain risk. In general SC risks can be classified as operational and disruption risk (Olson, 2011). Operational risks comprise of day-to-day disturbances in SC operations e.g., lead time, demand fluctuations etc. These risks are predictable whereas disruption risks are low in frequency and predictability but have high impact. Natural disasters like 
earthquakes, tornados; man-made catastrophes such as nuclear explosion, fire, wars, strikes etc. are the examples of disruption risks (Olson, 2011). Such disruptions have immediate strong impact on parts of SC networks located at the region of disrupting event. The impact is then propagated to the other parts of SC networks causing a ripple effect on overall SC performance.

Almost all the papers reviewed for this study argue that the current impact of the outbreak is already severe, and the medium-to-long-term impacts are expected to be higher than that of any other major outbreaks of the past. 938 of the Fortune 1000 companies experienced severe negative hit within first couple of months of the outbreak of the virus in China (WHO, 2020). All the 1000 largest companies of the world got severely impacted as they all have multiple facilities, and suppliers in the quarantined areas. A pandemic of such scale is considered a low frequency high impact (LFHI) event causing SC disruptions.

The researchers have explained, although with varying rigor, how the current pandemic situation is different from other supply chain (SC) risks and SC disruptions. The quick spread of the virus across almost all geographic regions of the globe has contributed to the spiralling effect of the pandemic. Both local and global supply chains got affected as one or multiple parts of the supply chains either stopped operation or operated at a lower level (Ivanov, 2020b). As the effect of the pandemic cascaded through various tiers of SC it is termed to have 'ripple effect' (Ivanov, Sokolov, \& Doglui, 2014). Even, the downstream (demand) side of the supply chains got affected. For some products such as health and hygiene products e.g., masks, sanitizers, cleaning agents, vitamin supplements there is sudden surge in demand. At the beginning of lockdown in different regions demand for essential items like food and grocery suddenly spiked due to panic buying behaviour of the consumers (Hobbs, 2020). Later, consumers started to rely more on on-line purchases and shy away from physical in-store buying (Singh, Kumar, Panchal, \& Tiwary, 2020). Such change in consumer behaviour created additional challenge on the supply chains in terms of product delivery channel and networks. Moreover, due to loss of employment and income or due to the fear of the same consumers started to look for bargain price and shift towards low-cost brands. To summarize, the pandemic has disrupted multiple tiers of supply chains in multi-faceted manner and the impacts are in no way transient rather they are gradually propagating from one point to another and evolving in terms of scale and type of commotions. Therefore, 
researchers unanimously argued that the pandemics is a special kind of SC disruption risk characterized by the following three features i) Long-term existence and unpredictable scaling of the outbreak, ii) simultaneous propagation of the effects of disruption and the pandemic itself and iii) simultaneous disruptions in all levels of SC network e.g., supply, demand, logistics and more.

\section{Key Issues Covered}

Table 2 presents the key issues covered in the research articles reviewed for this study. Major areas of focus include-SC resilience, viability, sustainability, ambiguity, and recovery plan.

Table 2: Research Focus/ Key Issues Covered in Literature

\begin{tabular}{lc}
\hline Research focus/ key issues covered & No. of articles \\
\hline SC resilience & 7 \\
\hline SC viability & 2 \\
\hline SC sustainability & 3 \\
\hline Dealing with ambiguity & 1 \\
\hline Recovery plan/model & 7 \\
\hline
\end{tabular}

a. SC Resilience

Eight out of twenty research articles reviewed for this study have evaluated $\mathrm{SC}$ resilience amid the pandemic. The current state of resilience of the major supply chains was reviewed and future agenda to enhance SC resilience are discussed. SC resilience means an SC network's ability to withstand disruptive events and recovery to a robust state of operation and regain its normal performance (Ivanov, 2020a). Risk mitigation inventories, subcontracting capacities, backup supply and transportation infrastructure, omni-channel and data-driven real-time monitoring and visibility systems are established SC resilience measures. In consonance with this, Hobbs (2020); McMaster et al. (2020); Haren and Simchi-Levi (2020) and others critiqued the just in time (JIT) and/or Lean SC models as being efficient and effective under normal circumstances but vulnerable to exogeneous disruptions and demand/supply shocks that the world is experiencing during the current pandemic situation. To tackle supply disruptions, McMaster et al. (2020); and Rapaccini, Saccani, Kowalkowski, Paiola and Adrodegari (2020) and others 
advocated for adjusting sourcing mix in terms of number of suppliers and their diverse geographical location and building up inventory and time buffer. They also proposed on leveraging collaboration and relationship with SC partners through open communication and equitable value distribution. Similarly, Hobbs (2020) argued for building collaborative buyer-seller relationship to enhance trust as such to minimize panic buying behaviour of the customers. She proposed that businesses should have contingency plans to deal with sudden labour shortages, and/or disruptions to transportation and supply network. She also calls for special support from governments to ensures smooth flow of essential goods in the economy. Referring to the recent trend of 'local food' for freshness, health, and economic reasons; she presumes that as an aftermath of the pandemic, reliance on local supply networks may intensify. Choi (2020), Singh et al. (2020); Linton and Vakil (2020) and others emphasized on the need for responsive logistic systems to ensure SC resilience during disruptions. In this regard, Singh et al. (2020) proposed truck-drone synchronized delivery system for supplying essential items. They also proposed a simulation based public distribution system (PDS) supported by integrated warehouse and backup warehouses to deliver essential items across the country. Quick adaptation of manufacturing facilities and switching to businesses of goods deemed essential during the pandemic (e.g., automobile manufacturers switching to manufacturing of ventilators, oxygen cylinders; textile and fashion industries producing personal protective equipment, gloves, masks, chemical factories producing sanitizer, cleansing agents and others) has been referred and appreciated by researchers as evidence of SC resilience (Singhnet al., 2020; Betti \& Heinzmann, 2020 and others). However, Ivanov and Das (2020) argued that traditional SC risk resilience practice of proactive redundancies in the form of holding some weeks of safety inventory, backup suppliers, subcontracting facilities and others are inadequate to tackle the overarching and gradually propagating effect of the current pandemic. They proposed a shift toward real-time contingent responses rather than building proactive redundancies. However, they attested the benefits of proactive management focusing on the creation of flexible redundancies. Flexible redundancy is characterized by rapid global crisis detection and response systems supported by robotics, automated production, and distribution networks. 
b. SC Viability

Viability is a concept referring to an underlying SC property overarching agility, resilience, and sustainability. Two of the research articles considered in the SLR of this study have focused on SC viability.

Ivanov (2020b) has presented a timeline of transformations in SC structures and research focus since 1990. He delineates that lean, responsive, and globalized SCs gradually evolved to being sustainable through their accountable actions toward nature and societal interests; strengthened resilience and learned to utilized digital technology. He also argued that the current COVID 19 pandemics has put the existing SC frameworks i.e., lean, agile, sustainable, resilient, and digital to test because there is lack of a holistic approach around these frameworks as such to guide their roles and interplays as an integrated whole. Thereby, Ivanov (2020b) proposes that SC response to disruptions should be considered at the scale of survivability or viability so that market collapses can be avoided, and flow of goods and services are secured despite mammoth, geographically spread, multitiered, long term propagation of pandemic. Viability as a concept has been extensively developed in ecology and biological system. SCM literature thus borrows a dynamic systems approach from biological science to view the players/ participants of SC as an ecosystem with interdependent interacting activities (Byrne, Dimitrov, Teti et al. (2018). Through a thorough analysis of wide-range relevant literature Ivanov (2020b) presented viable supply chain (VSC) model. Adaptable structural designs for supply-demand allocations and mechanisms for transitions between structural designs are the pillars of VSC model. This model will help SC professionals to design SCs that will adapt to any positive and/or negative disturbances as such to tackle any shortterm or long-term disruptions through societal and economic transformations.

Ivanov and Dolgui (2020a) asserted that current COVID 19 outbreak substantiates the necessity of analysing viability of SCs. They corroborated that conceptualization and implementation of intertwined supply networks (ISNs) are essential to ensure viability of SCs under high impact disruptions with ripple effects. They elaborated that traditional view considers car production as the final output goal of an automotive SC or production of some electronic devises to be the ultimate performance goal of electronic industry SCs. But ISNs view the goal of automotive SCs should be providing 
mobility service to society and that of electronic goods SCs should be providing communication service to society. Therefore, analysis of disruptions from ISN viewpoint is concerned with long-term securing of mobility and communication, hence ensuring viability. Building upon the resemblance of ISNs to ecological systems Ivanov and Dolgui (2020a) have illustrated how viability can be developed and ensured through dynamic game-theoretic modelling of a biological system.

c. SC sustainability

Sustainable business models pursue triple bottom line (TBL) - profit, planet, and people (Alhaddi, 2015). It helps companies do responsible business which enhances long-term survivability of the businesses. As presented in previous section, sustainability is one of the major prerequisites for viable SC structure. In fact, focus on sustainability is vital because it promotes proactive initiatives to identify and manage impacts of business operation on employees, workers, partners, and suppliers in the value chain let alone on local communities and the planet as a whole. Two of the research papers reviewed for this study focused on how sustainability of SCs from societal perspective has been affected by the pandemic.

Majumder, Shaw and Sinha (2020) argued that sustainability issues have broadly been overlooked especially in the context of emerging economies. Low wage, forced overtime, poor health and safety practices, substandard working conditions and threats of lay-off are some of the most common social sustainability issues of supply chains. The current pandemic has caused millions of job losses especially for blue collar workers (Betti \& Heinzmann, 2020). Majumder et al. (2020) revealed that power dominance of retail brands, unauthorized subcontracting of manufacturing work, use of contract labour by suppliers are the major causes of troubling social sustainability issues in supply chain players operating in emerging economies. Due to power dominance, the retail brands maintain their profit margin despite changes in the costs of the factors of production. They transfer the burden of cost cutting to suppliers. Fierce pressure of cost cutting results prevalence of poverty pay, unauthorized subcontracting and use of contract labour devoid of any job security let alone social security. Moreover, retail brands typically pay after delivery, in case of any downslide in demand they cancel or postpone orders that already have been completed or in 
production. Business risks are thus transferred onto the suppliers (Trautrims, Schleper, Cakir \& Gold, 2020; Leitheiser et al., 2020 and Majumber et al., 2020). On the other hand, upon sudden upsurge of demand, suppliers are pressurized to fulfil new orders in minimum time. The fear of losing contracts obliges suppliers to chase forced over time, unauthorized subcontracting and others contrasting social sustainability. Trautrims et al. (2020) have referred these social sustainability issues as modern slavery risks of SC. They argued that COVID 19 pandemic has enhanced the risk of modern slavery due as SCs in general being overwhelmed by the scale, extend and unpredictability of the pandemic are concentrating on short-term strategies to ensure business continuity. Thereby sustainability issues are being overlooked or pushed back. For example, to meet sudden demand surge of essential goods during the pandemic retailers need an urgent expansion of their supplier base leaving out scopes of comprehensive modern slavery risk assessment. Moreover, due to travel restrictions, physical audits of suppliers and their workforces are postponed or cancelled. Besides that, many businesses are operating with lower number of staff and many staff are relocated to line functions to ensure smooth flow of products. Hence, organizational capacity to detect and remediate instances of labour exploitation has reduced. This means that some SCs has become less transparent. Industries that heavily rely on migrant workers are negatively affected by lock downs and mobility restrictions. In such situations, governments as well as businesses have relaxed modern slavery prevention measures to ensure quick flow of labour. COVID 19 thus made SCs vulnerable in terms of social sustainability.

d. Dealing with Ambiguity

Gunessee and Subramanian (2020) argued that literature in relation to SC disruptions due to LFHI events or black swan events missed out the issue of ambiguity. Ambiguity is the imprecision involved in any decision-making situation in terms of judgement, assessment and forecasts of the factors associated with the decision. SCM and operations management (OM) decisions are affected by ambiguities in multi-faceted terms e.g., performance, information, causal, role, relational, processing time, uncertainty of probabilities and others. As ambiguities are distinct from risks (that can be projected with probability distribution and other statistics) Gunessee and 
Subramanian (2020) asserts that decision-making under ambiguity should also be distinct. Based on a foundation of behavioural decision theory (BDT) he proposed a generic SC decision-making framework to embed ambiguity in SC context. The framework is empirically demonstrated in the paper by using the COVID 19 pandemic situation as a case of SC disruption with multiple classes of ambiguity. Gunessee and Subramanian (2020) has also introduced the concept of ambiguity coping mechanism as a blend of organizational and individual strategies. Organizational coping strategies are built on the idea of mitigation and preparedness, whereas individual coping strategies are behaviourally embedded.

\section{e. Recovery Model}

Although all the research articles have provided some generic recommendations to tackle the effects of the pandemic on SCs only six of them have proposed specific recovery models to be adopted.

Paul and Chowdhury (2020) have developed a production recovery model for manufacturers of essential items. They assumed single product manufacturing with limited capacity (enough to meet normal time demand). In the recovery model they have factored additional costs of capacity enhancement and emergency sourcing and collaboration to meet the sudden surge in demand of the essential goods. Upon incorporating cost of new machinery, overtime, hiring of human resources, urgent purchase from back up or new supplier and others using mathematical equations a constraint recover model has been developed with an objective to meet increased demand and maximize total profit in the recovery window. They also have conducted scenario analysis with varying values additional demand and costs.

Singh et al. (2020) proposed truck-drone synchronized delivery system for continuing last mile delivery in highly infected regions. They also have developed an optimization network of public distribution system through simulation to mitigate and manage disruptions in the logistic systems of essential items e.g., food and health care products.

Ivanov (2020b) presented a viable supply chain (VSC) model and contended on the necessity of the VSC perspective for recovery from SC disruptions under the pandemic. The VSC model is built upon four viewpoints i.e., structural, dynamic 
state, performance, and control. Structural view represents SC structures activated through adaptation and recovery actions, state view portrays transition of SC structures over time in response to disturbances and disruptions, performance view illustrates the SC performance reactions to the stressors of different severity and the control view embodies the feedback loops of recovery processes.

Through a dynamic game-theoretic modelling Ivanov and Doglui (2020a) demonstrated an intertwined supply network (ISN) model. They argued that unlike the linearly directed SCs the ISN model exhibit multiple behaviours in buyer-supplier relations in interconnected or even competing SCs and thereby more suitable for collaboration and co-evolvement in response to longstanding, high impact disruptions like the current pandemic.

In another article Ivanov and Doglui (2020b) theorized a notion of digital supply chain twin which is a computer-based model to represent SC network states and interplay among them at any given moment in real time. They have done a thorough analysis of the conditions surrounding the design and implementation of digital twins for managing SC disruption risks. Digital twins are characterized by their capability of capturing the real time disruption data, analytics, end to end visibility, mapping of SC networks and decision support. Therefore, Ivanov and Doglui (2020b) asserted that digital twins are urgently needed not only to handle SC shocks and adaptations amid the current pandemic but also for design and implementation of post-pandemic recovery strategies.

Choi (2020) elaborated on issues related to in-person service delivery businesses such as music lesson, personal and beauty care, barber shop etc. under corona virus pandemic and suggested mobile service operation (MSO) as a recovery model. She defined traditional in-person service deliveries as static service operation (SSO) model. She proposed quantification of the impact of the pandemic in terms of consumer dis-utilities arising from concerns related to hygiene, travel, physical contact, and others. Mathematical equations to project demand, expected profit and consumer surplus were developed and tested with scenarios of SSO and MSO. Based on the results of analysis she asserted MSO model for recovery and continuity of in-person service delivery businesses.

Rapaccinia et al., (2020) recommended a four stage COVID 19 recovery model. Stage one is termed as calamity. This phase is considered to be few days since the outbreak. At this stage building awareness and analysing data to understand the 
impact is necessary. Within weeks the second phase actions termed as quick and dirty should be undertaken. At this phase companies should adopt health and safety precautions, secure work force and collaborate with SC partners and customers to find solutions. Then the restart phase evolves within months. At this phase elasticity of the SC is put to test. Companies need to adjust capacities to increased demand or bounce back to a reduced level of operation. The final phase is the new-normal state that may continue for years. At this phase understanding the enduring changes in business and socio-economic environment is essential. SC professionals may be required to negotiate and implement new logistic systems, business models, SC networks, structures, communication, and collaboration under the next-normal.

\section{Contexts of the Research}

More than half to the research articles reviewed were written in the context of global supply chains in general. However, six of them have analysed the impact of pandemic from localized contexts. For example, Rapaccinia et al. (2020) elaborated the scenario of Italian manufacturing firms. Majumder et al. (2020) used data from Indian manufacturers and 19. Leitheiser et al. (2020) used data from manufacturers in Bangladesh to portray the perspective of South Asian suppliers of big brand retailers. Singh et al. (2020) too have written their paper from Indian context, whereas Hobbs (2020) revealed the reality of Canadian SC and Choi (2020) represented a specific type of SC in Hongkong.

Although most of the articles discussed general SC issues, nine of them have investigated the situation for industry specific SCs. Hobbs (2020) and Singh et al. (2020) focused on food supply chain. Paul and Chowdhury (2020) analysed the manufacturing SCs of essential goods i.e., food, toiletries, cleaning items, disinfectants, sanitizers, medicine, gloves, masks etc. Majumder et al. (2020); Leitheiser et al. (2020) and McMaster et al. (2020) presented issues related to apparel manufacturing. however, the focus of Rapaccinia et al. (2020) was manufacturing SCs in general. Kumer, Raut, Narwane and Narkhede (2020) delineated on retail SCs; and Choi (2020) presented the situation of in-person service delivery SC amid the pandemic. Analysis of data and the reporting of the results of those analyses are fundamental aspects of the conduct of research. Accurate, unbiased, complete, and insightful reporting of the analytic treatment of data (be it quantitative or qualitative) must be a component of all research reports. Researchers in the field of psychology use numerous approaches to the 
analysis of data, and no one approach is uniformly preferred as long as the method is appropriate to the research questions being asked and the nature of the data collected. The methods used must support their analytic burdens, including robustness to violations of the assumptions that underlie them, and they must provide clear, unequivocal insights into the data.

\section{Theoretical Underpinning of the Research}

The research papers can be classified into five categories in terms of the theoretical basis of the studies. Table 3 presents the distribution of the papers in this regard.

Table 3: Distribution of research papers in terms of their theoretical basis

\begin{tabular}{l|c}
\hline Theoretical basis & No of research paper \\
\hline Theories of resilient SC & 8 \\
\hline Dynamic systems theory & 3 \\
\hline Sustainability theory & 2 \\
\hline Service delivery theory & 2 \\
\hline Decision theories under uncertainty & 3 \\
\hline
\end{tabular}

Studies by Ivavon (2020a); Paul and Chowdhury (2020); McMaster et al. (2020); Hobbs (2020); Ketchen Jr. and Craighead (2020); Choi, Rogers and Vakil (2020); de Sousa Jabbor et al. (2020); and Govindarajan and Bagla (2020) are based on theories of resilient SC. Ivanov (2020b); Ivanov and Dolgui (2020a); Ivanov and Dolgui (2020b); Singh et al. (2020) and Ivanov and Das (2020) have used dynamic systems theory in their analysis. Analysis done by Gunessee and Subramanian (2020) and Kumar et al. (2020) was built on decision theories under uncertainty. Majumder et al. (2020); Trautrims et al. (2020) and Leitheiser et al. (2020) have analysed the impact of COVID 19 pandemic on SCs from the perspective of sustainability theory. Choi (2020) and Rapaccinia et al. (2020) deployed service delivery theory in their proposed recovery strategies.

\section{Methodologies Employed}

Nine out of the twenty studies reviewed for this research have done descriptive and conceptual analysis of theories related to SC disruptions. The objectives were mainly to develop frameworks or models to analyse the situation, project the short and long-term impacts of the pandemic and/or formulate strategies to manage and recover from the disruption. Two of the studies namely Paul and 
Chowdhury (2020); Choi (2020) developed mathematical optimization models for determining recovery strategies out of the pandemic. Three studies viz Singh et al. (2020); Ivanov (2020b); Ivanov and Das (2020) have done simulation and scenario analysis.

In terms of sources of data, most of the researchers (thirteen articles out of twenty) have relied on academic literature, policy documents and survey data published by different international and national agencies like world economic forum (WEF), international monetary fund (IMF), world health organization (WHO) and others. Data collected and published by reputed business consultancy firms or publishers like McKinsey International, Wall Street Journal were also used by the researchers. Seven studies e.g., Majumder et al. (2020); Rapaccinia et al. (2020); Choi et al. (2020), Singh et al. (2020); Ivanov (2020b); Ivanov and Das (2020) and Paul and Chowdhury (2020) have used primary data for their analysis.

\section{Short and Long-term Impact of the Pandemic}

Major disruptions in SCs caused by the pandemic due to its unique nature in terms of scale, coverage, propagation, unpredictability, and others are already explained in Section 4.1. This subsection presents the specific impacts as observed and projected by researchers.

Closing and opening of facilities at different echelons of SCs at different time due to gradual propagation of the disease and lock down measures taken by authorities has resulted a prolonged spiralling effect that aggravated disturbances of SC operations (Ivanov, 2020a; 2020b) and disrupted transportation and distribution networks (Hobbs, 2020).

During the closure and lock down periods, panic buying of food and other essentials created demand shock (Hobbs, 2020; Singh et al., 2020; Paul \& Chowdhury, 2020). Due to uncertainty in supply of food and other essential items; some customers have started exploring local sources.

On the other hand, Rapaccinia et al., (2020); Kumar et al. (2020) and others argue that sales of non-essential items and services are experiencing huge decline during the pandemic due to several reasons e.g., loss of income, fear of losing income, restrictions on movement and gatherings and others. Moreover, customers are shifting to low-cost brands and has started to prefer purchasing online and home delivery of items. Researchers such as also argue that such changes in consumer behaviour is likely to prevail in the long run. 
Another major effect of the pandemic is the increased vulnerability of unskilled workforce and upstream suppliers located in emerging economies. Majumder et al. (2020) and Trautrims et al. (2020) suggested that due to higher bargaining power of the retailers, suppliers in emerging economies are facing several problems such as order cancellation and/or deferral, delay of payment, nonpayment of prepared but cancelled orders and others. That means the cost of disruption is being transferred to low margin suppliers which is ultimately being translated in to pay cut and/or job cut of workers. On the other hand, suppliers of essential goods are being pressed to increase production at lowest possible cost, thereby ending up with situations of forced overtime, poverty pay, contract labour, substandard and/or unsafe working condition and others.

\section{Recommendations surfaced from literature}

Researchers have suggested some immediate action plans and long-term recommendations to combat the SC disruptions caused by the pandemic. Pulling on recent and historical examples of the immediate responses of well-structured renowned SCs across the world almost all the researchers have made following suggestions for immediate implementation-

- Exploring alternate sources of supply in different geographical locations (Hobbs, 2020; Ivanov \& Das, 2020; Ketchen Jr. \& Craighead, 2020; Govindarajan \& Bagla, 2020).

- Rerouting distribution networks such that lock-down regions can be bypassed (Trautrims, et al., 2020; Singh et al., 2020 and others).

- Tapping alternate distribution channels. In other words, go online as much as possible. For this purpose, SCs needs to be restructured as such to house omnichannel distribution network (de Sousa Jabbor et al., 2020; Hobbs, 2020; McMaster et al., 2020; Kumar et al., 2020; and Ketchen Jr. \& Craighead, 2020).

- Add-in home delivery services (de Sousa Jabbor, Jabbor, et.al., 2020; Singh et al., 2020; Choi, 2020; and Kumar et al., 2020).

- Make adjustment in the facilities, buy necessary items, and put required equipment in place to pen operations following health-hygiene rules (Paul \& Chowdhury 2020; Rapaccini et al., 2020; Choi, 2020; and Kumar et al., 2020). 
- To meet increased demand; secure supply of raw materials and workers, make use of unutilized capacities, explore opportunities of subcontracting production, plan for additional shifts and over-time (Paul \& Chowdhury, 2020; Ivanov \& Das, 2020; Choi, 2020; and Ketchen Jr. \& Craighead, 2020).

Apart from the above-mentioned immediate response plans, researchers have proposed several long-term strategies as such to enhance resilience, sustainability, and viability of the SCs. In fact, majority of the articles reviewed for this study have thrived on theorizing SC disruptions like the current pandemic and formulate recovery model and strategies for long-run survivability. For instance, Ivanov (2020a); Ivanov and Doglui (2020a; 2020b); Majumder and Shaw (2020); Gunessee and Subramaniam (2020); Choi et al. (2020) and de Sousa Jabbor et al. (2020) recommended restructuring SCs in a way to ensure end to end visibility, seamless collaboration among the partners through value, cost and risk sharing, real time data sharing and communication, collaborative design, and flexible distribution network. They suggested shift from traditional linear SC model to SC networks. Ivanov and Doglui (2020a) categorically asserted that ISN is essential for survivability of SCs under disruption situations like the current pandemic. They also prompted the necessity of digital supply chain twins and use of industry 4.0 technologies such as robotics, block chain technology, Internet of things (IoT); data analytics, and others for implementing ISN and digital twins (Ivanov \& Doglui, 2020b). Kumar et al. (2020); Ivanov and Das (2020); Paul and Chowdhury (2020) and others attested the necessity of adopting industry 4.0 technologies in the form of collaborative design, real time visibility of items on $\mathrm{SCs}$, creation of virtual experience (try on) for customers and much more.

Rapaccini et al. (2020) advocated the need for servitization in the new normal era. By servitization they meant increasing customer surplus and value through add-on service strategies supported by digital breakthroughs such as smart connected products, industrial internet platforms, predictive analytics, digital offerings, and others. Choi (2020) suggested redesigning in-person service business models such as to bring them closer to customers or rendering services at customer premises.

Drawing on the fact of increased vulnerability of supply chain players with low bargaining power and the concern of social sustainability aroused thereby; 
Trautrims et al., 2020; Leitheiser et al., 2020; and Majumber et al., 2020 recommends restricting $\mathrm{SCs}$ as equitable and collaborative network. They proposed building long-term supportive relationship with low-end (lower bargaining power) suppliers and practicing ethical outsourcing behaviour. They also called for policy and regulatory support and financial subsidies from governments for maintenance and recovery of social sustainability.

\section{Conclusion}

Through SLR this research has summarized the research related to SCs amid the COVID 19 pandemic in terms of the main focuses, contexts, theoretical basis, methodologies adopted, and recommendations provided to combat the crisis. Long-term recovery models and strategies proposed for future new-normal (after the pandemic is gone) world are also discussed. Practitioners can refer to the findings especially the summary of recommendations while devising strategies and operational plans for overcoming the disruptions caused by the pandemic and for long-term continuity of operation as such to withstand and absorb similar shocks and disruptions in future. The simulation models proposed by the researchers can be used by practitioners to project the scale and versatility of such disruptions. The findings of the study can be treated as the background for future research not only on SC disruptions during and aftermath of pandemics but also on SC risk management, resilience, survivability, and sustainability in general. However, as only about nine months have elapsed since the outbreak has started, the relevant literature is not yet comprehensive in any way. Many research questions are still untapped. Anyway, researchers in future will be able to build their research agenda based on the summary of literature presented in this study. For example, ISNs are suggested to be the desired SC structure to enhance SC resilience, sustainability, and long-run survivability. But how to design and implement ISN, what are the relevant costs, requirement of new skills, change management issues and others are some practical questions to be answered. What are the challenges and costs of deploying industry 4.0 technologies? How to up skill SC professionals to adapt to the demands of jobs in new normal era? To what extent the simulation and in real life situations? How effective and practicable are the recovery models recommended in literature? How will be the transition to the new-normal era? Future researchers must collaborate with practitioners to unfold answers to the above questions. 


\section{References}

Alhaddi, H. (2015). Triple bottom line and sustainability: A literature review. Business and Management Studies, 1(2), 6-10.

Bell, E., Bryman, A., \& Harley, B. (2018). Business research methods. Oxford: Oxford university press.

Betti, F., \& Heinzmann, T. (2020). COVID-19: How companies are changing track to join the fight [www. document]. In World Econ. Forum. Retrieved from https://www. weforum. org/agenda/2020/03/from-perfume-to-hand-sanitisertvs-to-face-masks-how-companies-arechanging-track-to-fight-covid-19/ (Accessed on May 22, 2020)

Byrne, G. D., Dimitrov, L. Monostori, Teti, R., van Houten, F., \& Wertheim, R. (2018). B iologicalisation: Biological transformation in manufacturing. CIRP Journal of Manufacturing Science and Technology, 21, 1-32.

Choi, T. M. (2020). Innovative "bring-service-near-your-home" operations under Corona-virus (COVID-19/SARS-CoV-2) outbreak: Can logistics become the messiah? Transportation Research Part E: Logistics and Transportation Review, 140. https://doi.org/10.1016/j.tre. 2020.101961 (Accessed on August 20, 2020).

Choi, T. Y., Rogers, D., \& Vakil, B. (2020, March 27). Coronavirus is a wake-up call for supply chain management. Harvard Business Review. Retrieved from https://www.hbr.org (Accessed on August 10, 2020).

Cooper, D. R., \& Schindler, P. S. (2008). Business Research Methods. New Delhi, India: TaTa McGraw Hill Education Private Limited.

de Sousa Jabbour, A. B. L., Jabbour, C. J. C., Hingley, M., Vilalta-Perdomo, E. L., Ramsden, G., \& Twigg, D. (2020). Sustainability of supply chains in the wake of the coronavirus (COVID19/SARS-CoV-2) pandemic: lessons and trends. Modern Supply Chain Research and Applications. 631-3871. Retrieved from https://doi.org/10.1108/MSCRA-05-2020-0011 (Accessed on August 20, 2020).

Govindarajan, V., \& Bagla, G. (2020). As covid-19 disrupts global supply chains, will companies turn to India. Harvard Business Review, 25(05). Retrieved from https://hbr. org/2020/05/ascovid-19-disrupts-global-supply-chains-will-companies-turn-to-india (Access on 14 July 2020)

Gunessee, S., \& Subramanian, N. (2020). Ambiguity and its coping mechanisms in supply chains lessons from the Covid-19 pandemic and natural disasters. International Journal of Operations \& Production Management, 40(7/8) 1201-1223. Retrieved from https://doi.org/10.1108/ IJOPM-07-2019-0530. (Accessed on August 17, 2020)

Haren, P., \& Simchi-Levi, D. (2020). How coronavirus could impact the global supply chain by mid-March. Harvard Business Review, 28. Retrieved from https://hbr.org/2020/02/howcoronavirus-could-impact-the-global-supply-chain-by-mid-march?ab=hero-subleft-1, (Accessed on September 5, 2020).

Hobbs, J. E. (2020). Food supply chains during the COVID-19 pandemic. Canadian Journal of Agricultural Economics/Revue canadienne d'agroeconomie, 68, 171-176. Retrieved from http://doi.org/10.1111/cjag.12237 (Accessed on August 17, 2020).

Ivanov, D., \& Dolgui, A. (2020b). A digital supply chain twin for managing the disruption risks and resilience in the era of Industry 4.0. Production Planning \& Control. 1-14 Retrieved from https://doi.org/10.1080/09537287.2020.1768450 (Accessed on July 13, 2020). 
Ivanov, D. (2020b). Viable supply chain model: integrating agility, resilience, and sustainability perspectives-lessons from and thinking beyond the COVID-19 pandemic. Annals of Operations Research. 1, 1-21. Retrieved from https://doi.org/10.1007/s10479-020-03640-6 (Accessed on July 10, 2020).

Ivanov, D., \& Dolgui, A. (2020a). Viability of intertwined supply networks: extending the supply chain resilience angles towards survivability. A position paper motivated by COVID-19 outbreak. International Journal of Production Research, 58(10), 2904-2915.

Ivanov, D., \& Das, A. (2020). Coronavirus (COVID-19/SARS-CoV-2) and supply chain resilience: A research note. International Journal of Integrated Supply Management, 13(1), 90-102.

Ivanov, D. (2020a). Predicting the impacts of epidemic outbreaks on global supply chains: A simulation-based analysis on the coronavirus outbreak (COVID-19/SARS-CoV-2) case. Transportation Research Part E: Logistics and Transportation Review, 136, 101922. Retrieved from https://doi.org/10.1016/j.tre.2020.101922 (Accessed on July 10, 2020).

Ivanov, D., Sokolov, B., \& Dolgui, A. (2014). The Ripple effect in supply chains: trade-off 'efficiency-flexibility-resilience'in disruption management. International Journal of Production Research, 52(7), 2154-2172.

Ketchen Jr, D. J., \& Craighead, C. W. (2020). Research at the Intersection of Entrepreneurship, Supply Chain Management, and Strategic Management: Opportunities Highlighted by COVID19. Journal of Management, 46(8), 1330-1341.

Kumar, M. S., Raut, R. D., Narwane, V. S., \& Narkhede, B. E. (2020). Applications of industry 4.0 to overcome the COVID-19 operational challenges. Diabetes \& Metabolic Syndrome: Clinical Research \& Reviews, 14(5), 1283-1289.

Leitheiser, E., Hossain, S. N., Sen, S., Tasnim, G., Moon, J., Knudsen, J. S., \& Rahman, S. (2020). Early Impacts of Coronavirus on Bangladesh Apparel Supply Chains. The Regulation of International Supply Chains (RISC). Retrieved from https://www.cbs.dk/files/cbs.dk/risc _ report_-_impacts_of_coronavirus_on_bangladesh_rmg_1.pdf. (Accessed on July 13, 2020).

Linton, T., \& Vakil, B. (2020). Coronavirus is proving we need more resilient supply chains. Harvard Business Review, March 5, 2020.

Majumdar, A., Shaw, M., \& Sinha, S. K. (2020). COVID-19 debunks the myth of socially sustainable supply chain: A case of the clothing industry in South Asian countries. Sustainable Production and Consumption. 24, 150-155. Retrieved from https://doi.org/10.1016/j.spc. 2020.07.001 (Accessed on July 13, 2020).

McMaster, M., Nettleton, C., Tom, C., Xu, B., Cao, C., \& Qiao, P. (2020). Risk Management: Rethinking Fashion Supply Chain Management for Multinational Corporations in Light of the COVID-19 Outbreak. Journal of Risk and Financial Management, 13(8), 173-188. Retrieved from https://doi.org/10.3390/jrfm13080173 (Accessed on July 13, 2020).

Olson, D. L. (2011). Supply chain risk management: tools for analysis. New York: Business Expert Press.

Paul, S. K., \& Chowdhury, P. (2020). A production recovery plan in manufacturing supply chains for a high-demand item during COVID-19. International Journal of Physical Distribution \& Logistics Management. 0960-0035. Retrieved from https://doi.org/10.1108/IJPDLM-04-20200127 (Accessed on July 13, 2020).

Petticrew, M. (2001). Systematic reviews from astronomy to zoology: myths and misconceptions. BMJ, 322(7278), 98-101. Retrieved from https://doi.org/10.1136/bmj.322.7278.98 (Accessed on September 5, 2020). 
Rapaccini, M., Saccani, N., Kowalkowski, C., Paiola, M., \& Adrodegari, F. (2020). Navigating disruptive crises through service-led growth: The impact of COVID-19 on Italian manufacturing firms. Industrial Marketing Management, 88, 225-237.

Singh, S., Kumar, R., Panchal, R., \& Tiwari, M. K. (2020). Impact of COVID-19 on logistics systems and disruptions in food supply chain. International Journal of Production Research. 1-16 Retrieved from https://doi.org/10.1080/00207543.2020.1792000 (Accessed on August 17, 2020).

Stebbins, R. A. (2001). Exploratory research in the social sciences, (Vol. 48). London: Sage Publications.

Trautrims, A., Schleper, M. C., Cakir, M. S., \& Gold, S. (2020). Survival at the expense of the weakest? Managing modern slavery risks in supply chains during COVID-19. Journal of Risk Research. 1067-1072. Retrieved from https://doi.org/10.1080/13669877.2020.1772347 (Accessed on August 17, 2020).

Verma, S., \& Gustafsson, A. (2020). Investigating the emerging COVID-19 research trends in the field of business and management: A bibliometric analysis approach. Journal of Business Research, 118, 253-261.

World Health Organization. (2020). WHO Director-General's opening remarks at the media briefing on COVID-19-11 March 2020. Retrieved from https://www.who.int/dg/speeches/ detail/whodirector-general-s-opening-remarks-at-the-media-briefing-on-covid-19---11-march-2020 (Accessed on July 30, 2020). 